\title{
Analysis of the SHP2 enhancer for the use of tissue specific activation tagging in Arabidopsis thaliana
}

\author{
Antonio Chalfun-Junior*, Jurriaan J. Mes, Marco Busscher and Gerco C. Angenent \\ Business Unit Bioscience, Plant Research International, Wageningen, The Netherlands.
}

\begin{abstract}
Activation tagging is a powerful tool to identify new mutants and to obtain information about possible biological functions of the overexpressed genes. The quadruple cauliflower mosaic virus (CaMV) $35 S$ enhancer fragment is a strong enhancer, which is most commonly used for this purpose. However, the constitutive nature of this enhancer may generate lethal mutations or aberrations in different plant organs by the same overexpressed gene. A tissue-specific activation tagging approach may overcome these drawbacks and may also lead more efficiently to the desired phenotype. For this reason the SHATTERPROOF2 (SHP2) promoter fragment was analysed for enhancer activity. The SHP2 gene is involved in dehiscence zone development and expressed during silique development. The aim of the experiments described here was to identify a dehiscence zone specific enhancer that could be used for tissue-specific activation tagging. The chosen SHP2 enhancer fragment was found to be expressed predominantly in the dehiscence zone and showed enhancer activity as well as ectopic expression activity. This activity was not influenced by its orientation towards the promoter and it was still functional at the largest tested distance of $2.0 \mathrm{~kb}$. Based on these results, the SHP2 enhancer fragment can potentially be used in a tissue-specific activation tagging approach to identify new Arabidopsis mutants with an altered dehiscence zone formation.
\end{abstract}

Key words: Arabidopsis, development, pod shattering, transcription factors, mutants.

Received: May 2, 2005; Accepted: October 24, 2005.

\section{Introduction}

Activation tagging has become an upcoming tool to generate mutant plants. It is an alternative approach for gene function analysis, because loss-of-function mutations has its limitation in cases of functional gene redundancy (Arabidopsis Genome Initiative, 2000). Activation tagging was proposed as a novel gene isolation method in which a gene is either ectopically or constitutively overexpressed compared to normal expression levels (Walden et al., 1994). Walden et al. (1994) designed a T-DNA based activation tagging approach to identify and isolate novel genes from tobacco, and since then it has been largely applied using either T-DNA insertion strategies (Borevitz et al., 2000; Ito and Meyerowitz, 2000; Lee et al., 2000; van der Graaff et al., 2000; Weigel et al., 2000; Huang et al., 2001) or transposon based approaches (Wilson et al., 1996; Marsch-Martinez et al., 2002). This technology has been applied successfully to many plant species like Arabidopsis, rice, tomato, petunia and tobacco (Weigel et

Send correspondence to Antonio Chalfun-Junior. Universidade Federal de Lavras, Laboratório Central de Biologia Molecular, 37200-000 Lavras, MG, Brazil. E-mail: chalfunjunior@ufla.br.

*Present address: Universidade Federal de Lavras, Laboratório Central de Biologia Molecular, Lavras, MG, Brazil. al., 2000; Jeong et al., 2002; Zubko et al., 2002; Ahad et al., 2003; Mathews et al., 2003).

Activation tagging is based on strong transcriptional enhancer sequences that can activate gene expression in the vicinity of the site where the enhancer was inserted into the genome. The most commonly used enhancer is a quadruple combination of the cauliflower mosaic virus (CaMV) $35 \mathrm{~S}$ enhancer (Odell et al., 1985; Hayashi et al., 1992). These $4 \times 35 S$ enhancer elements have been reported to strongly enhance endogenous gene expression rather than ectopically or constitutively overexpress genes (Neff et al., 1999; van der Graaff et al., 2000). It has been demonstrated that it can stimulate gene expression of neighboring genes independently of its orientation, up to a distance of $3.6 \mathrm{~kb}$ (Weigel et al., 2000) or even up to $5.0 \mathrm{~kb}$ (Chalfun-Junior $e t$ al., 2005).

It is tempting to use this technique in a random-like approach to isolate new mutants and analyse in more detail the overexpressed genes. In some cases, the mutant displays a phenotype that can either be directly associated with the gene function of the activated gene (Zubko et al., 2002 ) or may provide an indication of the pathway in which the gene is involved (Kardailsky et al., 1999; Zhao et al., 2001; Yuen et al., 2003). The activation tagging method has also been used as a novel approach to isolate 
suppressor mutants of known mutant phenotypes (Neff et al., 1999; van der Graaff et al., 2003). However, when searching for specific mutants with a more specific phenotype, the $4 \times 35 S$ enhancer is not very attractive to use, as it will induce aberrations in plant tissues other than the specific one that was intended to be modified. In that case, tissue-specific enhancement could directly lead to the mutants of interest. To test this hypothesis we have characterized a tissue-specific enhancer that may be applicable to efficiently generate activation mutants with an altered pod shattering phenotype.

Precocious pod shattering is a phenomenon in which fruits lose their seeds before harvesting time, generating high losses of agronomic crops, e.g., rapeseed. Engineering for shatter resistant plants allow the plants to grow until the fruits are fully ripened, resulting in an optimal product quality and increased crop yield. The closely related $M A D S$ box transcription factors SHATTERPROOF1 (SHP1) and SHATTERPROOF2 (SHP2) control seed dispersal in Arabidopsis by regulating the development of the dehiscence zone (Ferrandiz et al., 2000; Liljegren et al., 2000; Ferrandiz, 2002). In shp1shp2 double mutant plants, the dehiscence zone is completely absent and the fruits fail to open.

Here, we describe the identification of a SHP2 enhancer taken from its natural promoter, which contains all necessary characteristics required for a tissue-specific activation approach.

\section{Material and Methods}

\section{Plant material and transformation}

Constructs were introduced into Arabidopsis thaliana ecotype Col-0 using Agrobacterium tumenfaciens strain GV3101 and the floral dip method (Clough and Bent, 1998). For selection of transformants, seeds were surface sterilized by vapor phase sterilization (http://plantpath. wisc.edu/ afb/vapster.html), and selected on medium containing kanamycin. Plants were grown in soil, under normal greenhouse conditions $\left(22^{\circ} \mathrm{C}, 14 / 10 \mathrm{~h}\right.$ light/dark $)$.

\section{Constructs}

\section{The SHP2 enhancer fragment}

Primers were designed at $-1275 \mathrm{bp}$ and $-55 \mathrm{bp}$ from the transcription initiation site of the SHP2 gene (forward primer SHP2F 5'-GTCGACAAGCTTAAGTTCTTTCTT GAAATG-3', reverse primer SHP2R 5'-GTCGACAA GCTTCACTTAACTGCTGCTTCAAC-3'). Both primers were extended with sequences for digestion sites to facilitate subcloning (HindIII and SalI sites underlined). DNA of Arabidopsis thaliana ecotype Col-0 was used as template for PCR amplification. Using these primers a band of the expected 1220 bp was obtained, cloned (in pGEMTEasy ${ }^{\circledR}$, Promega) and sequenced to confirm its identity.

\section{SHP2 enhancer fused to minimal -47-35S::GUS}

The minimal $-47-35 S$ promoter GUS vector, GUSXX-47 (Pasquali et al., 1994) was obtained from J. Memelink, (Leiden University, Leiden, The Netherlands). The SHP2F primer was extended with a HindIII site and the reverse primer with a SalI site, the fragment amplified and ligated in the HindIII-SalI site upstream of the $-47-35 S$ promoter, which was fused to the GUS reporter gene. The whole fragment was subcloned in pBINPLUS (van Engelen et al., 1995) using HindIII-KpnI, resulting in vector pGD751.

\section{SHP2 fragment fused to the pFBP1::GUS}

Both SHP2 primers were extended with both HindIII and SalI sites to facilitate the cloning of the vectors described next. Several constructs were generated to test the enhancer activity of the $S H P 2$ fragment. For that reason the SHP2 fragment (as a HindIII-HindIII fragment) was ligated upstream of the $F B P 1$ promoter present in vector $\mathrm{pFBP} 12 \mathrm{E}$ (Angenent et al., 1993). This resulted in a sense fusion of the SHP2 enhancer to the 'short' 220 bp pFBP1::GUS (pGD418).

The SalI-SalI fragment was introduced in the SalI digested pFBP12E vector, resulting in a sense fusion of the $S H P 2$ enhancer to the 'long' $1040 \mathrm{bp} \mathrm{FBP1}$ promoter fused to the GUS reporter gene (pGD393). For the other constructs, the SalI-SalI fragment of the cloned PCR SHP2 enhancer fragment was first subcloned in pBluescript $\mathrm{SK}^{+}$ vector (Promega) in both orientations (pARC012 and pARC013). The 'long' pFBP $1: \because G U S$ fragment was also subcloned as an EcoRI-EcoRI from pFBP12E into pBluescript $\mathrm{SK}^{+}$vector in both orientations (pARC014 and pARC015). A ClaI-XhoI fragment containing the sense or antisense $S H P 2$ enhancer was then inserted adjacent to the pFBP $1:: G U S$ fragment in both vectors pARC014 and pARC015. This resulted in an antisense fusion of the SHP2 enhancer upstream of the 'long' $p F B P 1:: G U S$ fragment and in vectors where the $S H P 2$ enhancer was downstream of this fragment in either sense or antisense orientation. The total inserts of these vectors were subcloned in the binary vector pBINPLUS ${ }^{\circledR}$ by using $X b a \mathrm{I}$ and $K p n \mathrm{I}$. All vectors were checked in detail by restriction sites and fragment length analysis.

\section{GUS activity}

Histochemical localization of GUS activity was performed as described by Jefferson et al. (1987).

\section{Results}

\section{Tissue specificity of the SHP2 enhancer}

It has been shown previously that the $S H P 2$ gene is expressed in the dehiscence zone of Arabidopsis siliques (Savidge et al., 1995; Liljegren et al., 1998; Liljegren et al., 2000). To test whether a putative $S H P 2$ enhancer fragment 
contains the cis-acting elements and all its tissue specific regulating sequences, a $1220 \mathrm{bp}$ upstream sequence was tested for its promoter/enhancer activity. This $1220 \mathrm{bp}$ fragment was chosen from -1275 bp to -55 bp upstream of the transcription initiation site, which was also 8 bp upstream of a putative TATA box. This $1220 \mathrm{bp} S H P 2$ promoter fragment contains a CarG-box like sequence (Savidge et al., 1995), which is the putative AGAMOUS binding site and which is very likely to be important for its regulation. This promoter fragment (from now on referred to as the SHP2 enhancer) was fused to a minimal $-47-35 S$ promoter, which was fused to the GUS reporter gene (GUSXX-47) (Pasquali et al., 1994). This construct will allow the analysis of its transcriptional enhancer activity and tissue specificity. This binary vector (Figure 1A) and a control construct, which carries only the empty vector (GUSXX-47), were introduced into Arabidopsis plants ecotype Col-0. In Table 1, the GUS expression patterns of 24 analyzed T1 plants are summarized. No GUS expression was observed in plants containing only the empty vector. In most of the GUS positive plants, GUS staining was observed in the dehiscence zone (Figure 1B). This expression in the dehiscence zone was seen at earlier stages during flower development (Figure 1C). Besides GUS expression in the dehiscence zone, some plants also displayed GUS expression in other tissues, for instance in pollen grains (Figure 1D), ovules (Figure $1 \mathrm{E}$ ), funiculus (Figure $1 \mathrm{~F}$ ), nectaries (Figure $1 \mathrm{G}$ ) and the vascular junction at the receptacle (Figure $1 \mathrm{H}$ ). Similar to the results obtained here, SHP1 and SHP2 genes were previously described to be expressed in tissues like septum, ovules and funiculus (Ma et al., 1991), in addition to the dehiscence zone (Savidge et al., 1995; Liljegren et al.,
1998; Liljegren et al., 2000). In some plants, no GUS staining was observed. Although no molecular analyses were performed on them, it is very likely that these plants were not transgenic or were not expressing the GUS gene properly (Table 1). Based on these results, it can be concluded that the 1220 bp SHP2 enhancer still contains the dehiscence specific regulatory sequences of the SHP 2 promoter.

\section{Activity of the SHP2 enhancer}

Enhancers are defined as cis-acting DNA sequences that can increase the transcription level of genes by the binding of specific transcription factors. Full promoter activity also requires the DNA region containing the TATA box directly upstream of the transcription start site (Lewin, 2000). Enhancers usually can function in either orientation and separated from a minimal promoter domain. To obtain an enhancer for efficient tissue-specific activation tagging, these features are essential. To test all these features of the SHP2 enhancer, several constructs were generated (Figure 2).

Because enhancers are not able to act alone (Lewin, 2000), a minimal or natural promoter is necessary. Therefore, the FLORAL BINDING PROTEINI (FBPI) promoter was chosen because this petunia promoter regulates expression in whorl 2 and 3 of the flower (petals and stamens respectively) (Angenent et al., 1993). In petunia, two different lengths of the $F B P 1$ promoter fragment were analysed, a 220 bp 'short' promoter and a 1040 bp 'long' FBP1 promoter. Both promoter fragments showed the same specificity and levels of expression in petunia (Angenent et al., 1993). Analysis of both promoter fragments in Arabidopsis showed the same results as for petunia (unpublished re-

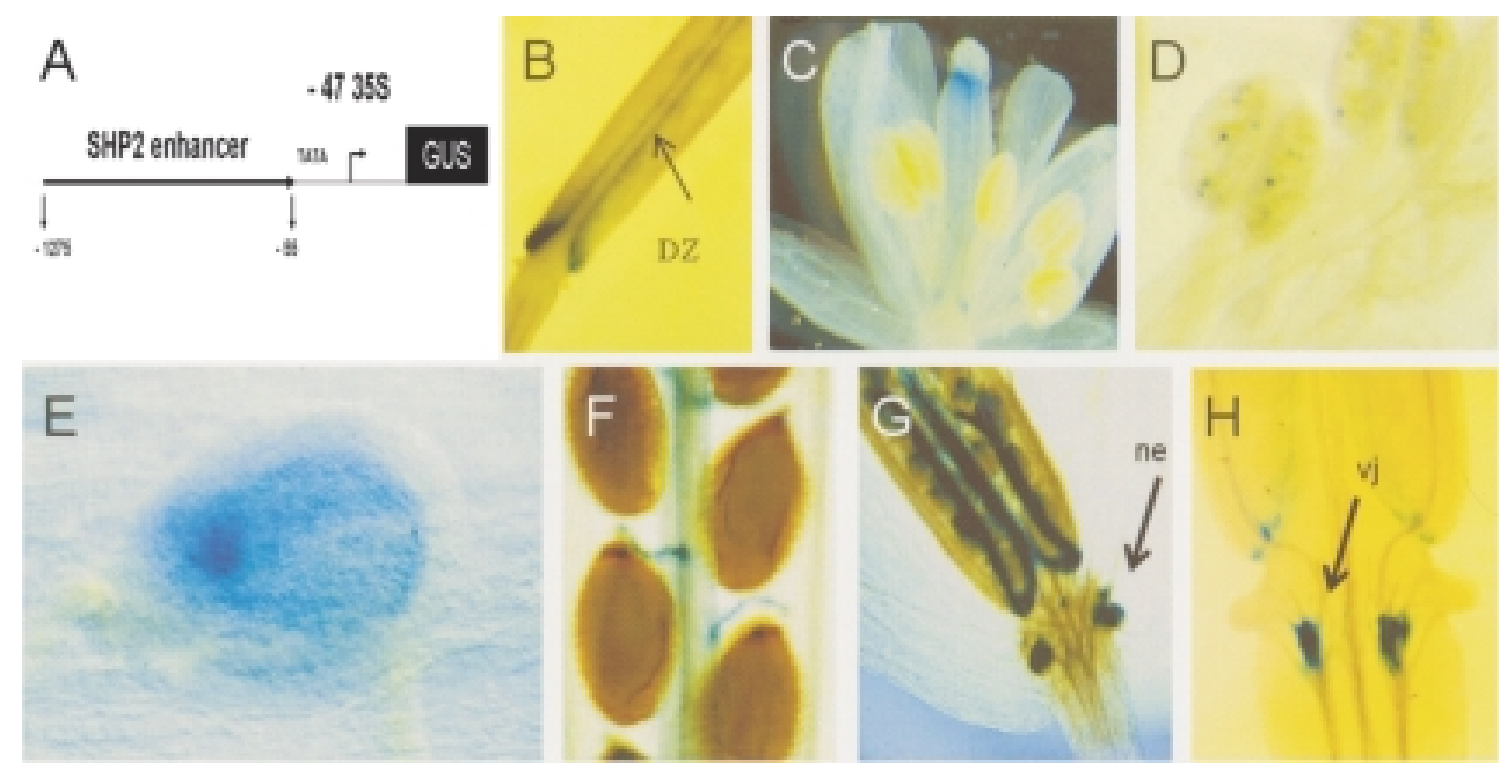

Figure 1 - GUS expression pattern in Arabidopsis plants containing the construct $S H P 2$ fused to the minimal $35 S$ promoter (-47-35S:: GUS). (A) Schematic representation of the construct (which is not drawn to scale). (B) Arabidopsis silique showing GUS expression in the dehiscence zone (DZ, arrow). (C) A young flower with GUS expression in the DZ. GUS expression is also present in (D) pollen grains, (E) ovules, (F) funiculus and (G) nectary (ne), and $(\mathrm{H})$ vascular junction $(\mathrm{vj})$ in the receptacle. 
Table 1 - GUS expression of SHP2 enhancer-GUS plants (pARC751).

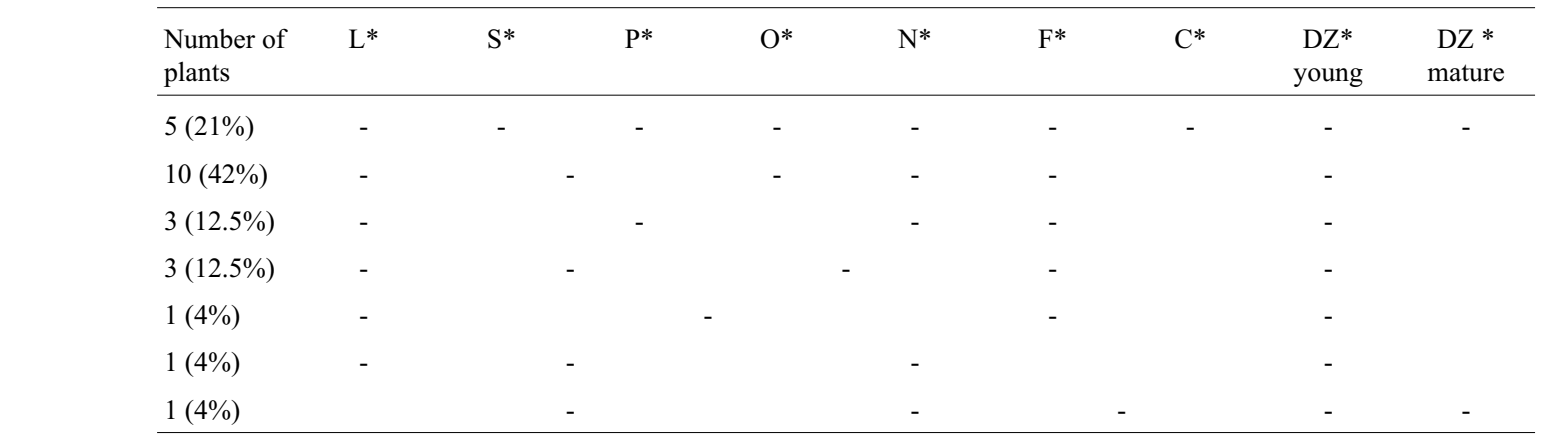

* L (Leaf); S (Sepals); P (Pollen); O (Ovules); N (Nectary); F (Funiculus); C (Carpels); DZ (dehiscence zone).

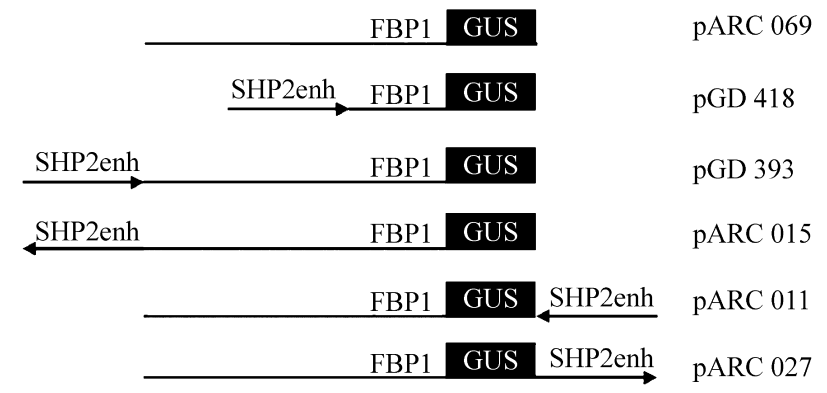

Figure 2 - Schematic representation of the constructs in which the $S H P 2$ enhancer was fused to the $p F B P 1: \because G U S$ promoter-gene construct in different orientations. pARC069: the $p F B P 1:: G U S$ construct used as control. pGD418: SHP2 in sense orientation upstream of the short version of the pFBP1 promoter. pGD393: the $S H P 2$ enhancer fragment is located upstream of the long $p F B P 1:: G U S$ version. pARC015: the SHP2 is also located upstream of the long $p F B P 1:: G U S$ construct, however in antisense orientation. pARC011: the $S H P 2$ is placed downstream of the GUS gene in sense orientation and $S H P 2$ is placed in antisense orientation in the same long version of the $F B P 1$ promoter, in pARC027. This schematic representation is not drawn to scale.

sults). Therefore, as control, a binary vector harbouring the 'long' FBP1 promoter sequence fused to GUS was introduced into Arabidopsis plants. Several transgenic plants were obtained with different levels of GUS expression in petals (often very weak) and filaments (stronger) (Table 2 and Figure 3A, B). This result indicates that this promoter acts as expected, with the same specificity as in petunia (Angenent et al., 1993), and can be used to test the SHP2 enhancer. Figure 2 summarises the vectors that were used to test the SHP2 enhancer activity based on its ectopic expression in combination with the $F B P 1$ promoter. In the first two tester constructs, the $S H P 2$ enhancer was fused in sense orientation, with both the 'short' and the 'long' versions of the FBP1 promoter resulting in pGD418 and pGD393 respectively (Figure 2). These constructs were used to test whether the $S H P 2$ enhancer fragment could ectopically activate GUS expression in combination with the FBP 1 promoter and, moreover, whether the enhancer still keeps its tissue-specific activity when combined with a natural promoter. By using the 'short' and 'long' version of the FBP 1 promoter, the influence of the distance towards the promoter was analysed. The other three constructs should identify whether the SHP2 enhancer acts independently of its orientation and position related to the coding sequence. The results of the GUS staining of the transgenic Arabidopsis plants expressing these constructs are summarised in Table 2.

In general, all constructs that contained the SHP2 enhancer fused in either way to the pFBP1::GUS, showed the FBP1-driven expression in whorls 2 and 3 (Figure $3 \mathrm{C}$ ) and, also ectopic GUS expression in the dehiscence zone (Figure 3D). In whorls 2 and 3, the GUS expression driven by the FBP1 promoter was similar to or in some lines slightly enhanced compared to the expression observed in plants that contained the control construct with only the 'long' pFBP1::GUS construct (pARC069). The SHP2 enhancer region drove ectopic expression to the dehiscence zone, however it did not seem to promote up-regulation of the FBP1 promoter activity. As expected, this ectopic expression driven by the $S H P 2$ enhancer was mostly seen in the dehiscence zone tissue. However in some plants, GUS staining in pollen grains was observed as well (data not shown).

The distance of the SHP 2 enhancer relative to the promoter sequence did not seem to influence the frequency of plants showing ectopic expression in the dehiscence zone. When the SHP2 enhancer was situated downstream of the GUS gene (pARC011 and pARC027) (Figure 2), the enhancer was still able to ectopically activate the expression with the same frequency as observed for the upstream sense position of the SHP2 enhancer (Table 2).

The only construct that did not result in ectopic expression in dehiscence zone tissue was construct pARC015 (Table 2), which contains the SHP2 enhancer positioned upstream, in an anti-sense orientation, linked to the 'long' pFBP $1:$ GUS fragment. Out of fourteen T1 plants analysed, 10 showed expression in whorls 2 and 3 only.

\section{Discussion}

Tissue specific activation tagging is a novel approach to generate mutants for a specific trait of interest. Requirements for such a strategy are that: i) the used enhancer frag- 
Table 2 - GUS expression observed in tissues of transgenic Arabidopsis plants containing different constructs (see Figure 2).

\begin{tabular}{|c|c|c|c|c|c|c|c|c|c|c|}
\hline \multirow[t]{2}{*}{ Name } & \multirow[t]{2}{*}{ Construct } & \multirow{2}{*}{$\begin{array}{l}\text { N. of } \\
\text { plants }\end{array}$} & \multicolumn{3}{|c|}{ FPB1 expression } & \multicolumn{2}{|c|}{$\mathrm{DZ}^{*}$} & \multirow[t]{2}{*}{$\mathrm{N}^{*}$} & \multirow[t]{2}{*}{$\mathrm{O}^{*}$} & \multirow[t]{2}{*}{$\mathrm{V}^{*}$} \\
\hline & & & $\mathrm{P}^{*}$ & $\mathrm{~A}^{*}$ & $\mathrm{~F}^{*}$ & Young & Old & & & \\
\hline \multirow[t]{2}{*}{ pARC069 } & \multirow[t]{2}{*}{ Long $F B P 1:: G U S$} & 7 & + & + & + & - & - & - & - & - \\
\hline & & 6 & - & - & - & - & - & - & - & - \\
\hline \multirow[t]{5}{*}{ pGD418 } & \multirow{5}{*}{$\begin{array}{l}S H P 2 \text { enh sense } \\
\text { Short FBP1::GUS }\end{array}$} & 2 & + & + & + & - & - & - & - & - \\
\hline & & 2 & + & + & + & + & + & - & - & - \\
\hline & & 1 & + & + & + & - & - & - & + & - \\
\hline & & 1 & + & + & + & + & + & + & + & - \\
\hline & & 5 & - & - & - & - & - & - & - & - \\
\hline \multirow[t]{4}{*}{ pGD393 } & \multirow{4}{*}{$\begin{array}{l}S H P 2 \text { enh sense } \\
\text { Long FBP1::GUS }\end{array}$} & 16 & + & + & + & - & - & - & - & - \\
\hline & & 13 & + & + & + & + & + & - & - & - \\
\hline & & 9 & - & - & - & + & + & - & - & - \\
\hline & & 5 & - & - & - & - & - & - & - & - \\
\hline \multirow[t]{2}{*}{ pARC015 } & \multirow{2}{*}{$\begin{array}{l}S H P 2 \text { enh antisense } \\
\text { Long } F B P 1:: G U S\end{array}$} & 10 & + & + & + & - & - & - & - & - \\
\hline & & 4 & - & - & - & - & - & - & - & - \\
\hline \multirow[t]{5}{*}{ pARC011 } & \multirow{5}{*}{$\begin{array}{l}\text { Long FBP } 1:: G U S \\
S H P 2 \text { enh sense }\end{array}$} & 2 & + & + & + & - & - & - & - & - \\
\hline & & 13 & + & + & + & + & + & - & - & - \\
\hline & & 4 & + & + & + & + & + & - & - & + \\
\hline & & 2 & + & + & + & - & - & - & - & - \\
\hline & & 7 & - & - & - & - & - & - & - & - \\
\hline \multirow[t]{4}{*}{ pARC027 } & \multirow{4}{*}{$\begin{array}{l}\text { Long } F B P 1: \because G U S \\
S H P 2 \text { enh antisense }\end{array}$} & 1 & + & + & + & - & - & - & - & - \\
\hline & & 3 & + & + & + & + & + & - & - & - \\
\hline & & 1 & - & - & - & + & + & - & - & - \\
\hline & & 1 & - & - & - & - & - & - & - & - \\
\hline
\end{tabular}

* DZ (dehiscence zone) P (petals); A (anthers); F (filaments); N (nectary); O (ovule); V (vascular bundle).

ment shows tissue specificity, avoiding unwanted side effects in other tissues ii) the activity of the enhancer should still be functional at least at several kbs from the natural promoter or gene, increasing the efficiency that genes will be activated, and iii) the insertion in the genome should be carried out by a system that minimizes the chances of complex insertion integrations (Nacry et al., 1998), which can cause silencing of the introduced enhancer (Chalfun-Junior et al., 2003).

Here we show that the $1220 \mathrm{bp} S H P 2$ promoter fragment taken from the upstream sequence of the SHP2 gene contains most of the cis-regulatory sequences. It has been previously reported that the SHP2 gene is expressed in the dehiscence zone of the Arabidopsis silique, in addition to other tissues like septum, ovules and funiculus (Ma et al., 1991; Savidge et al., 1995; Liljegren et al., 1998; Liljegren et al., 2000). The SHP2 enhancer sequence chosen in our study is mainly expressed in the dehiscence zone, although GUS expression was also observed in ovules, funiculi and nectaries. The expression occasionally observed in a few pollen grains, nectaries and the vascular junction at the receptacle were not described previously. We did not test GUS expression driven by the complete endogenous SHP2 promoter in this same setup, which makes a comparison between published in situ hybridisation data and our data obtained with the enhancer studies more difficult. In conclusion, we demonstrated that it is possible to confer specific and ectopic expression of a particular gene by using an upstream enhancer sequence combined with minimal promoter elements.

The second prerequisite for an efficient activation tagging approach is that the enhancer activity should reach as far as possible from the minimal promoter elements (e.g., the TATA box). Based on the results obtained with the constructs in which the SHP2 enhancer was fused to the FBP1 promoter (in combination with the GUS reporter gene), we detected ectopic expression driven by the SHP2 enhancer in most of the combinations. In some of the plants, the GUS staining in the dehiscence zone was very strong and comparable with -47-35S::GUS transgenics. This was even the case when the enhancer was inserted downstream of the GUS gene, which resulted in GUS expression levels comparable with those for the upstream sense positions.

It still remains unclear why the construct pARC015 revealed no ectopic activation. This improper function may be specific for the FBP1 promoter and it is unlikely that this 


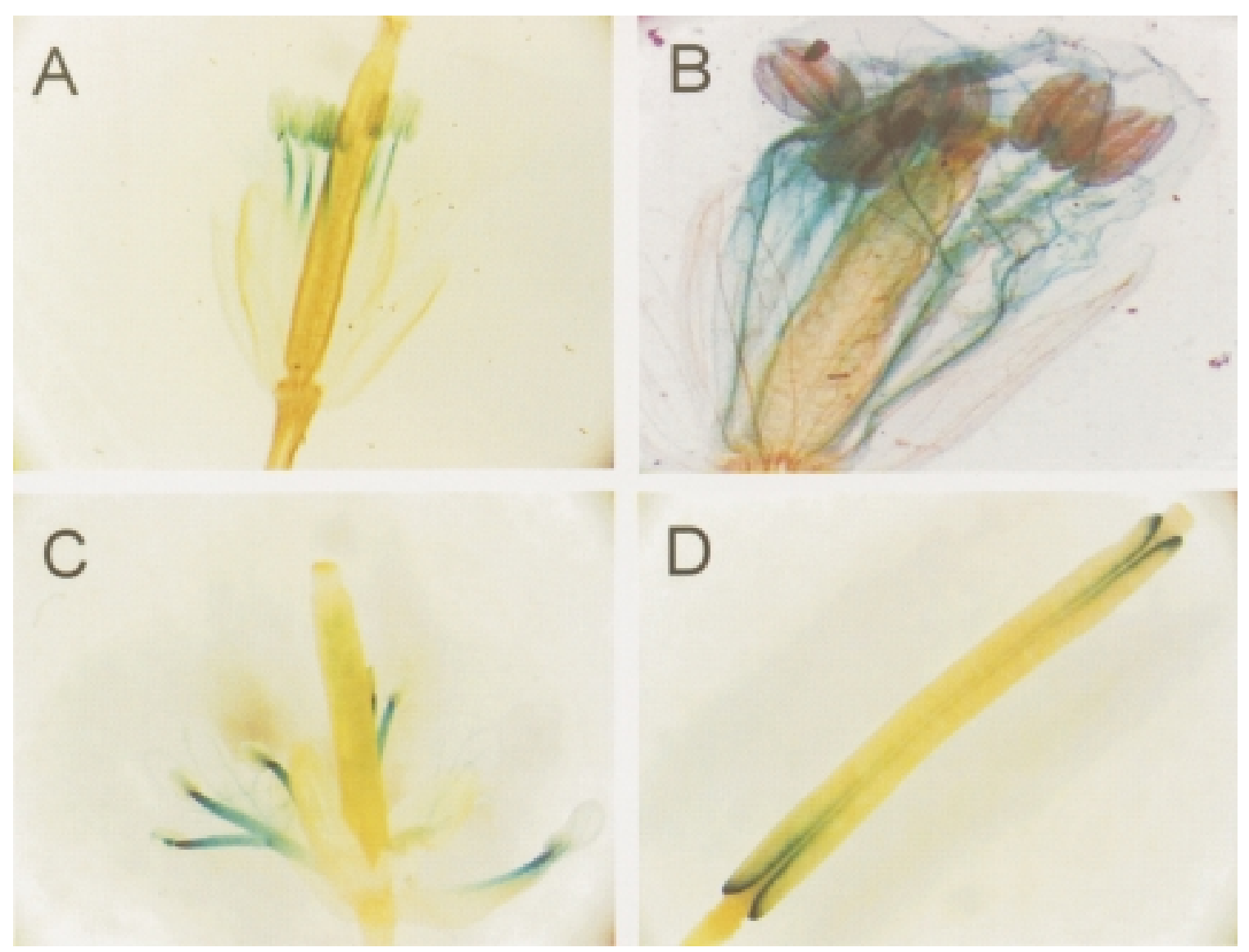

Figure 3 - GUS expression pattern in Arabidopsis plants containing the SHP2 enhancer inserted in the $p F B P 1: \because G U S$ construct (pGD418). (A-B) pFBP1::GUS (pARC069) flower, showing the FPB1-driven expression in whorls 2 and 3 (petals and stamens, respectively), (A) in stamens and (B) in petals. (C) Flower of a line containing pGD418 construct, showing GUS expression in petals (vasculature) and anther filaments, and weak expression in the ovules. (D) Silique of a pGD418 line. Besides the FBP1-driven expression in petals and filaments, ectopic GUS expression is observed in the dehiscence zone.

is a general feature for an enhancer inserted in antisense orientation upstream of a native promoter. Our results demonstrate that the enhancer activity acts over a distance of at least $2.0 \mathrm{~kb}$, making it interesting to explore it in a tissue-specific activation tagging strategy. When an even stronger activity would be required, it may be possible to create a tagging construct with a repeated $S H P 2$ enhancer, similar to experiments performed with the $35 S$ enhancer (Weigel et al., 2000; Marsch-Martinez et al., 2002). And this brings us to the third requirement for an efficient tagging strategy, i.e. avoidance of silencing, which could be induced by the insertion of repeated DNA sequences (Chalfun-Junior et al., 2003).

Based on the findings described by Marsch-Martinez et al. (2002) and our own observations on the methylation of T-DNA based activation tagging using the quadruple $35 S$ enhancer (Chalfun-Junior et al., 2003), we propose a transposon-based tagging strategy as being the most promising. Hopefully this strategy, in which the described $S H P 2$ enhancer could be used as tissue-specific enhancer, will lead to a better understanding of pod dehiscence and to novel approaches to control the shattering behaviour of crops.

\section{Acknowledgments}

The authors thank John Franken for helping with sectioning and taking pictures, Stefan de Folter for helping in the beginning of the experiments, and Marsja Meijer. Maarten Koornneef and Mark Aarts for helpful discussions. This work has been partially supported by CAPES-Brazil (BEX 1519/98-0).

\section{References}

Ahad A, Wolf J and Nick P (2003) Activation-tagged tobacco mutants that are tolerant to antimicrotubular herbicides are cross-resistant to chilling stress. Transgenic Res 12:615630.

Angenent GC, Franken J, Busscher M, Colombo L and van Tunen $\mathrm{AJ}$ (1993) Petal and stamen formation in petunia is regulated by the homeotic gene FBP1. Plant J 4:101-112.

Arabidopsis Genome Initiative (2000) Analysis of the genome sequence of the flowering plant Arabidopsis thaliana. Nature 408:796-815. 
Borevitz JO, Xia YJ, Blount J, Dixon RA and Lamb C (2000) Activation tagging identifies a conserved MYB regulator of phenylpropanoid biosynthesis. Plant Cell 12:2383-2393.

Chalfun-Junior A, Mes JJ, Mlynarova L, Aarts MGM and Angenent GC (2003) Low frequency of T-DNA based activation tagging in Arabidopsis is correlated with methylation of CaMV 35S enhancer sequences. FEBS Lett 555:459-463.

Chalfun-Junior A, Franken J, Mes JJ, Marsch-Martinez N, Pereira A and Angenent GC (2005) ASYMMETRIC LEAVES2LIKE 1 gene, a member of the AS2/LOB family, controls proximal-distal patterning in Arabidopsis petals. Plant Mol Bio 57:559-575.

Clough SJ and Bent AF (1998) Floral dip: A simplified method for Agrobacterium-mediated transformation of Arabidopsis thaliana. Plant J 16:735-743.

Ferrandiz C (2002) Regulation of fruit dehiscence in Arabidopsis. J Exp Bot 53:2031-2038.

Ferrandiz C, Liljegren SJ and Yanofsky MF (2000) Negative regulation of the SHATTERPROOF genes by FRUITFULL during Arabidopsis fruit development. Science 289:436-438.

Hayashi H, Czaja I, Lubenow H, Schell J and Walden R (1992) Activation of a plant gene by T-DNA tagging - auxin independent growth in vitro. Science 258:1350-1353.

Huang S, Cerny RE, Bhat DS and Brown SM (2001) Cloning of an Arabidopsis patatin-like gene, STURDY, by activation T-DNA tagging. Plant Physiol 125:573-584.

Ito T and Meyerowitz EM (2000) Overexpression of a gene encoding a cytochrome p450, CYP78A9, induces large and seedless fruit in Arabidopsis. Plant Cell 12:1541-1550.

Jefferson RA, Kavanagh TA and Bevan MW (1987) GUS fusions: Beta-glucuronidase as a sensitive and versatile gene fusion marker in higher plants. EMBO J 6:3901-3907.

Jeong DH, An S, Kang HG, Moon S, Han JJ, Park S, Lee HS, An $\mathrm{K}$ and An G (2002) T-DNA insertional mutagenesis for activation tagging in rice. Plant Physiol 130:1636-1644.

Kardailsky I, Shukla VK, Ahn JH, Dagenais N, Christensen SK, Nguyen JT, Chory J, Harrison MJ and Weigel D (1999) Activation tagging of the floral inducer FT. Science 286:19621965.

Lee H, Suh SS, Park E, Cho E, Ahn JH, Kim SG, Lee JS, Kwon YM and Lee I (2000) The AGAMOUS-LIKE 20 MADS domain protein integrates floral inductive pathways in Arabidopsis. Genes Dev 14:2366-2376.

Lewin B (2000) Genes XVII. Oxford University Press, Oxford, $990 \mathrm{pp}$.

Liljegren SJ, Ferrándiz C, Alvarez-Buylla ER, Pelaz S and Yanofsky MF (1998) Arabidopsis MADS-box genes involved in fruit dehiscence. Flow Newsl 25:9-19.

Liljegren SJ, Ditta GS, Eshed Y, Savidge B, Bowman JL and Yanofsky MF (2000) SHATTERPROOF MADS-box genes control seed dispersal in Arabidopsis. Nature 404:766-770.

Ma H, Yanofsky MF and Meyerowitz EM (1991) AGL1-AGL6, an Arabidopsis gene family with similarity to floral homeotic and transcription factor genes. Genes Dev 5:484-495.

Marsch-Martinez N, Greco R, van Arkel G, Herrera-Estrella L and Pereira A (2002) Activation tagging using the En-I maize transposon system in Arabidopsis. Plant Physiol 129:1544-1556.

Mathews H, Clendennen SK, Caldwell CG, Liu XL, Connors K, Matheis N, Schuster DK, Menasco DJ, Wagoner W,
Lightner J and Wagner DR (2003) Activation tagging in tomato identifies a transcriptional regulator of anthocyanin biosynthesis, modification, and transport. Plant Cell 15:1689-1703.

Nacry P, Camilleri C, Courtial B, Caboche M and Bouchez D (1998) Major chromosomal rearrangements induced by TDNA transformation in Arabidopsis. Genetics 149:641-650.

Neff MM, Nguyen SM, Malancharuvil EJ, Fujioka S, Noguchi T, Seto H, Tsubuki M, Honda T, Takatsuto S, Yoshida S and Chory J (1999) BAS1: A gene regulating brassinosteroid levels and light responsiveness in Arabidopsis. Proc Natl Acad Sci USA 96:15316-15323.

Odell JT, Nagy F and Chua NH (1985) Identification of DNA sequences required for activity of the cauliflower mosaic virus $35 S$ promoter. Nature 313:810-812.

Pasquali G, Ouwerkerk PB and Memelink J (1994) Versatile transformation vectors to assay the promoter activity of DNA elements in plants. Gene 149:373-374.

Savidge B, Rounsley SD and Yanofsky MF (1995) Temporal relationship between the transcription of two Arabidopsis MADS box genes and the floral organ identity genes. Plant Cell 7:721-733.

van der Graaff E, Dulk-Ras A, Hooykaas P and Keller B (2000) Activation tagging of the LEAFY PETIOLE gene affects leaf petiole development in Arabidopsis thaliana. Development 127:4971-4980.

van der Graaff E, Nussbaumer C and Keller B (2003) The Arabidopsis thaliana rlp mutations revert the ectopic leaf blade formation conferred by activation tagging of the LEP gene. Mol Genet Genomic 270:243-252.

van Engelen FA, Molthoff JW, Conner AJ, Nap JP, Pereira A and Stiekema WJ (1995) pBINPLUS: An improved plant transformation vector based on pBIN19. Transgenic Res 4:288290.

Walden R, Fritze K, Hayashi H, Miklashevichs E, Harling H and Schell J (1994) Activation tagging: A means of isolating genes implicated as playing a role in plant growth and development. Plant Mol Biol 26:1521-1528.

Weigel D, Ahn JH, Blazquez MA, Borevitz JO, Christensen SK, Fankhauser C, Ferrandiz C, Kardailsky I, Malancharuvil EJ, Neff MM, Nguyen JT, Sato S, Wang ZY, Xia YJ, Dixon RA, Harrison MJ, Lamb CJ, Yanofsky MF and Chory J (2000) Activation tagging in Arabidopsis. Plant Physiol 122:10031013.

Wilson K, Long D, Swinburne J and Coupland G (1996) A dissociation insertion causes a semidominant mutation that increases expression of TINY, an Arabidopsis gene related to APETALA2. Plant Cell 8:659-671.

Yuen CYL, Pearlman RS, Silo-suh L, Hilson P, Carroll KL and Masson PH (2003) WVD2 and WDL1 modulate helical organ growth and anisotropic cell expansion in Arabidopsis. Plant Physiol 131:493-506.

Zhao Y, Christensen SK, Fankhauser C, Cashman JR, Cohen JD, Weigel D and Chory J (2001) A role for flavin monooxygenase-like enzymes in auxin biosynthesis. Science 291:306-309.

Zubko E, Adams CJ, Machaekova I, Malbeck J, Scollan C and Meyer P (2002) Activation tagging identifies a gene from Petunia hybrida responsible for the production of active cytokinins in plants. Plant J 29:797-808.

Associate Editor: Klaus Hartfelder 